\title{
SUPRASORT - Dispositivos Supramoleculares Autorregulados Baseados na Complementaridade dos Pares de Base do ADN: Uma Tecnologia Biomimética e com Reconhecimento Molecular
}

Vasco Bonifácio

vasco.bonifacio@tecnico.ulisboa.pt $\bullet \bullet$

A natureza contempla uma enorme variedade de sistemas supramoleculares complexos, exibindo estruturas, propriedades e funcionalidades sem precedentes desde a nano- à macroescala. Exemplos fascinantes de estruturas supramoleculares em sistemas vivos incluem as células e suas funções autónomas, a estrutura de dupla hélice do ADN, a matriz extracelular dos tecidos e órgãos, entre outras. Neste sentido, os sistemas biológicos são uma extraordinária fonte de inspiração para o desenvolvimento de biomateriais supramoleculares funcionais com o intuito de mimetizarem as características estruturais, funcionais e a natureza dinâmica dos sistemas biológicos. Os biomateriais supramoleculares são extremamente atrativos, permitindo acomodar múltiplas moléculas bioativas num único sistema hierárquico, de uma maneira reversível e dinâmica, a fim de controlar o comportamento celular. De facto, a deteção, isolamento e separação de células é um tema relevante em engenharia de tecidos e medicina regenerativa que está longe de ser alcançado, atrasando o seu uso em clínica.

O projeto SUPRASORT visa desenvolver plataformas supramoleculares bioativas e quimicamente programáveis capazes de isolar e recrutar, de forma seletiva e autorregulada, células específicas de uma mistura heterogénea. Os biomateriais supramoleculares a desenvolver integram múltiplas biomoléculas, processadas via interações não covalentes com recurso a tecnologias verdes, extremamente versáteis e de baixo custo, com o intuito de mimetizar a estrutura complexa, a organização hierárquica, e a robustez mecânica da matriz extracelular nativa. Apesar de se prever a utilização de tais plataformas supramoleculares como biomateriais autorregulados para regeneração óssea, nomeadamente para regenerar fraturas ósseas extensas, a sua natureza adaptativa permitirá a integração de qualquer tipo de molécula bioativa a fim de regular virtualmente qualquer tipo de célula, tecido e/ou órgão e auxiliar efetivamente no processo regenerativo.
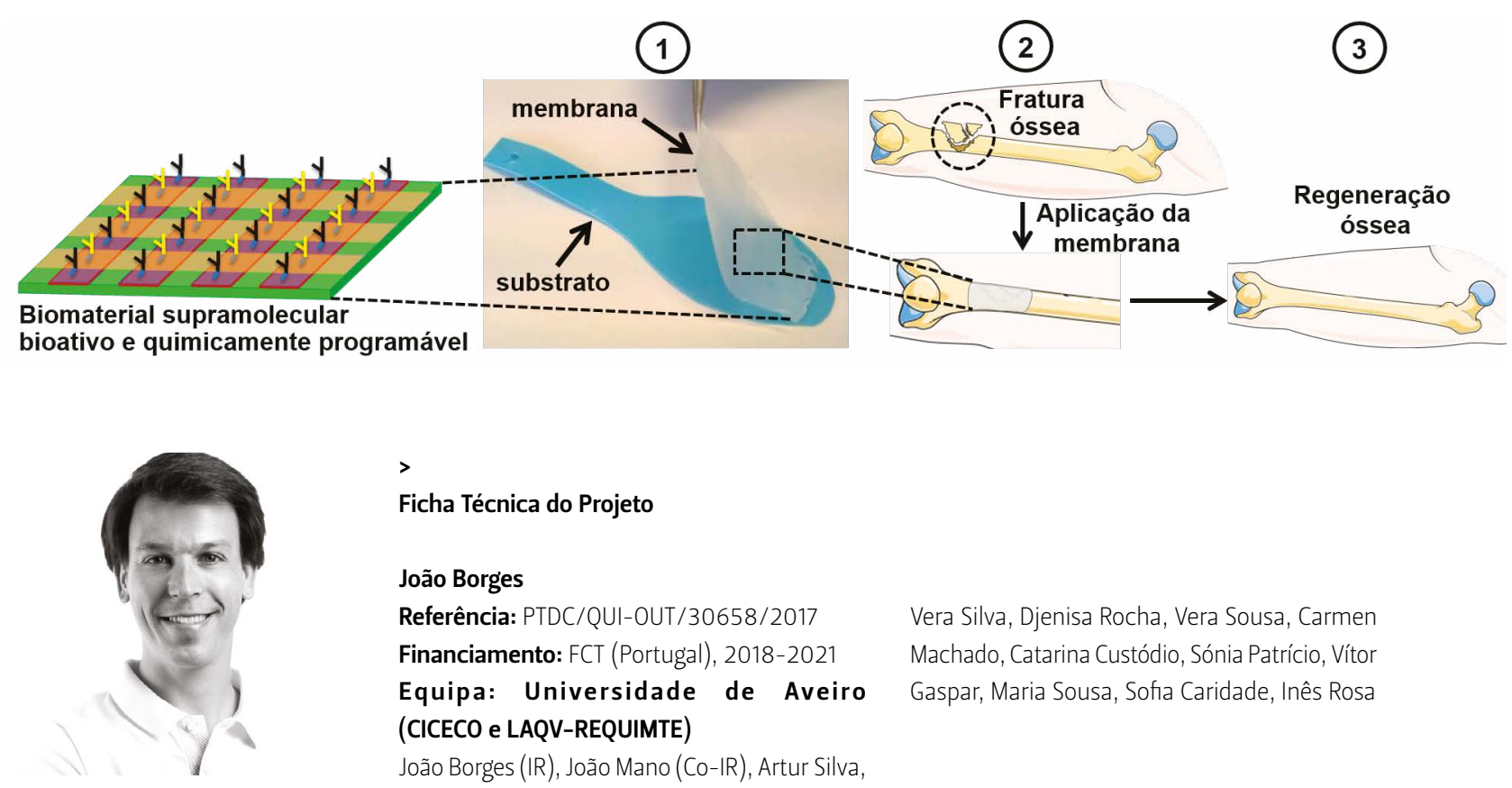

Ficha Técnica do Projeto

João Borges

Referência: PTDC/QUI-OUT/30658/2017

Vera Silva, Djenisa Rocha, Vera Sousa, Carmen

Financiamento: FCT (Portugal), 2018-2021

Machado, Catarina Custódio, Sónia Patrício, Vítor

Equipa: Universidade de Aveiro Gaspar, Maria Sousa, Sofia Caridade, Inês Rosa (CICECO e LAQV-REQUIMTE)

João Borges (IR), João Mano (Co-IR), Artur Silva, 